\title{
Reshaping diversity in a local classroom: Communication and identity issues in multicultural schools in the Netherlands
}

\author{
Mariëtte de Haan *, Ed Elbers
}

University of Utrecht, Faculty of Social Sciences/ASW Heidelberglaan 2, 3584 CS Utrecht, The Netherlands

\begin{abstract}
This study on peer collaboration in a multi-ethnic classroom examines variations in communication patterns that indicate particular interpretations of the school's pedagogy and reflect asymmetries between ethnic groups. These strategies are analyzed using a cross-contextual perspective focusing on the translation between more enduring, broader-scale phenomena and local ones. According to this perspective, the students' strategies must be seen as a dynamic interplay between: (i) local constructions responding in particular ways to institutional demands; (ii) experiences rooted in home socialization, and (iii) structural power relations expressed in positioning vis-à-vis the school as an institution.
\end{abstract}

(C) 2005 Elsevier Ltd. All rights reserved.

Keywords: Communication; Ethnicity; Classrooms; Location of culture; Cultural translation

\section{Introduction}

Migration flows lead to increasing contact between people who are socialized in diverse communities. Multi-ethnic classrooms are places where these diversities confront each other and accommodate to each other over longer periods of time and are

\footnotetext{
* Corresponding author. Tel.: +31 30 2537735/2531408; fax: +31 302534733 .

E-mail address: m.dehaan@fss.uu.nl (M. de Haan).
} 
therefore relevant locations to study processes of conflict, negotiation and accommodation. In this paper we present an analysis of classroom interaction in which the role divisions that are set up in patterns of collaboration, learning and co-teaching reflect an ethnically informed boundary between the students. In our study we found that, when minority and non-minority students collaborate in small groups on a maths task, a particular asymmetric collaboration pattern, referred to here as 'peer tutoring', takes place much more often than in groups with only minority students. Minority students, in turn, show a preference for more symmetric, peer-based collaboration patterns. Moreover, in the ethnically mixed groups, native Dutch students are invited to take up, and do take up, the role of the tutor, leaving the more dependent tutee role to the minority students. This pattern does not only imply a difference in how they interpret peer teaching and learning, it also implies an asymmetric division of responsibilities between students with clear ethnic boundaries.

How should we interpret such a pattern? This is the issue we deal with in this article. First, there is the question of how, in this particular case, cultural or figurative aspects (Holland et al., 1998) relate to structural or positional aspects. In other words, is an interpretation in terms of students' experiences with a particular kind of tutoring in other settings relevant here, i.e., is it appropriate to focus on the cultural 'stuff? Or is it more fruitful to look at power relationships that exist between these ethnic groups, more or less independently of the cultural form they take? And how do these two issues relate? A second question is the issue of time line and scale. With respect to time: to what extent can we say that these patterns were formed in the particular classroom these students have been in together for years? Do we see these patterns as the result of a particular classroom setting, an interactional history which started the moment the students came to be classmates? Or do we have to look for older patterns that evolved before that time? As for scale: can we conclude that other socializing experiences in other settings are relevant to explain what is happening in the classroom and do we accordingly address the scale of possible relevant phenomena? Or, can we instead confine our analytical perspective to the scale of a particular classroom?

Through our analysis we hope to show that the collaboration patterns can be seen as culturally informed interactive strategies which at the same time reflect particular power relations. Moreover, we argue that they are the result of local processes which accommodate diversity and status differences produced elsewhere and are brought into the classroom.

In other words, we consider the patterns to be particular local productions or reworkings of certain asymmetries and cultural contrasts that students are faced with in multi-ethnic settings. The issue of how these processes of translation and production can happen and how they relate to more enduring struggles and diversity encountered in other settings is the focus of this contribution.

We argue that a perspective on diversity across contexts is necessary to understand both local processes and more enduring ones. We hope to show that an exclusive focus on the location of production is unfruitful, as is a focus on 'general' non-situated processes. In the here and now of local practices, the broader and long term social and cultural patterns are used as resources for responding to the demands 
of the particular situation. At the same time, the here and now, seen as local arenas in which these resources are used to negotiate certain goals and identities, is the scene where these broader and more enduring patterns are articulated, reshaped or resisted.

\section{Theoretical perspectives}

We argue in favour of a cross-contextual perspective and draw from a number of theoretical sources for this. Firstly, there is the changing conceptualisation of culture and its relation to 'location', secondly there is theoretical work on the relationship between the figurative and the positional and how they are linked in local reproductions, and lastly we draw from theoretical perspectives that explicitly focus on the need to link the local and non-local in view of developing multiple-site perspectives on diversity.

\subsection{The location of culture}

In the past, culture has generally been defined by the ways groups 'cultivated' a given territory, as suggested by the etymological link to 'gardening' (Papastergiadis, 2000). Cultures are supposed to come from a particular place focussing on a certain spatial origin of the cultural practices and meanings that were formed. Cultures were seen as the ways people made sense of their world and the result of this effort was seen in terms of clearly bounded wholes and particular identities, where uniqueness and boundaries implied each other. In more recent work, the 'location of culture' has become an issue of debate, in particular in relation to globalisation and migration. Culture is no longer seen as tied to one particular location as intensified travel and new communication technologies make communities more dispersed and cultural forms in certain ways have become detached from specific locations.

This implies a need to focus on processes of cultural translation and on the ways local and non-local communities and their cultural practices are linked. The focus has shifted to processes of translation and exchange, to the 'in between' and to processes of cultural change. At the same time this has not led to a move away from the local and the present, as it is there and then that transition is produced. It has created a new awareness of what Bhabha (1994) calls 'the art of the present', a focus on those moments or processes where cultural differences are articulated rather than a focus on where they were initially formed.

As a result, identities now tend to be defined in terms of identity strategies rather than in terms of singular, static categories of gender or class, and this implies a focus on the transformation of identities. We think this perspective is fruitful for our analysis of classroom patterns of diversity in interaction as the focus is moved to both the articulation of difference under the local conditions of the classroom as well as to processes of the translation of resources, including the perceptions of power relations formed elsewhere and brought into the classroom. 


\section{2. 'Living through' the figurative and the positional}

Returning to our earlier question of what kind of explanations are relevant in terms of a culture-structure distinction, we consider it useful to first examine what are now called 'culturalist' and 'structuralist' explanations, which, in the past, were relied on to explain diversity issues in education. In culturalist explanations - this is sometimes referred to as the cultural discontinuity approach - diversity in classrooms is explained as the result of diversity in home socialization. The more socialization patterns at home differ from those at school, the more difficult the process of adapting to the school culture and the less likely it is that students are successful at school. In this kind of explanation, diversity is defined in cultural terms, meaning that it is seen as the result of a specific socialization process with particular meanings and behaviours that go together with and 'belong to' a particular group. A classic example of the cultural discontinuity perspective is the study by Heath (1983) in which she demonstrated that the language patterns of a middle class community were much more similar to literacy practices at school compared to the language patterns of both a white and a black working class community. The similarities between home and school helped the white middle class children to be more successful. For more examples, see the overviews in Cazden (1986), Mehan (1998), Eisenhart (2002), Gallego and Cole (2002), and Elbers and de Haan (2004).

In structuralist explanations, or explanations from a social reproduction perspective, differences between social groups are viewed from a more critical, political perspective. The focus is on power relationships and long-established inequalities. These inequalities are 'played out' in schools and the school is seen as one of the places where already established positions vis-à-vis power relationships are re-confirmed and re-constructed. A classic example of this approach is the work of Bourdieu and Passeron (1977); studies of resistance can be seen as a continuation of this approach (for instance, the work of Giroux, 1983). Both in classic accounts of reproduction theory and in more recent accounts, cultural differences becomes a matter of the specific forms status differences take. In this view, schools privilege certain forms of symbolic capital over other and cultural differences have no explanatory power in their own right. In this paper we argue that both perspectives bring out different analytical dimensions of the same phenomena. Such a view is in line with, for instance, the analytical distinction between positional and figurative identities made in Holland et al. (1998). The figurative then stands for the culturally constituted stories in which people express their judgments, their emotions and define their world, whereas the positional refers to one's social position, relative to that of others in terms of power relations and privileges. These figurative and positional aspects interact in numerous ways and it is Sherry Ortner's (1999) account of their relationship that we find particularly helpful. She shows how, from an agency perspective, the figurative is always expressed in a field of power relationships through stories of struggle, i.e., through social relationships that are never neutral but reflect histories of power inequalities. And, vice versa, she argues that people do not just submit, reject 
or reconstruct power relations but work through these relationships in ways that work for their lives; the result is that these power relationships are given a $\mathrm{cul}$ tural expression. In other words, when we consider how people actually 'live through' the structural and cultural dimensions, both dimensions do, of necessity, come together.

Further pursuing this line of thought, we think it is important to see diversity in classrooms as a result of diverse cultural heritages and power relations both taking on new forms, as both are reshaped under local conditions and become formative for each other when they are lived through in the here and now.

\subsection{A local reproduction perspective: looking across contexts and boundaries}

In studies on education, there has been an increasing interest in the local and situated character of explanations of diversity, as for instance in Lock Davidson's (1996) work on how academic identities are reworked in school settings and how being black comes with a profile of a high academic performer in one school setting and a profile of a low academic performer in another. These studies form, from a certain perspective, a rupture with the older traditions referred to above. Other studies have explicitly focussed on the links between, on the one hand, the situated and local and, on the other hand, the historical (the level of enduring practices). The local constructions enter into a complex relationship with the social and cultural reproduction of more structural and enduring processes (Levinson and Holland, 1996). Such studies rely on recent interpretations of culture, in line with those outlined above, and stress the active placement of individuals in between cultural traditions. Cultural heritage or past socialization patterns are regrouped, reproduced locally and are constructed under the influence of fields of power, contents, themes, and social relationships other than those the students brought with them when entering the classroom. Difference is not given but made in particular contexts, by making use of categories and conceptions taken from other contexts. Identity formation in the school context is seen as a particular cultural-historical production which both responds to, and is formative of, the movements, structures, and discourses beyond the school.

Our aim here is to build on the studies that explicitly advocate a double, crosscontextual perspective on the interpretation of the classroom data. In this particular case, this means that we will show how theoretical explanations of diversity that are based on a more structuralist, non-local approach are still relevant when they are brought together with explanations based on a local production perspective. In other words, we attempt to accomplish this double, cross-contextual perspective by developing multiple explanations, in particular explanations which rely on a combination of local production explanations and more structural explanations in an attempt to bring together long durée and situated perspectives. Moreover, we attempt to show how they are not just different perspectives that can be used consecutively but instead have to be seen as different levels of explanation that are interwoven and connected. 


\section{A study of collaborative learning in a multi-ethnic classroom: ethnically informed boundaries in practices of 'explaining'}

\subsection{Migrants and schooling in the Netherlands}

Large groups of migrants have come to the Netherlands since the sixties. The largest groups, which came for economic reasons, are from Turkey, Morocco, Surinam and the Antilles. In recent years, migrants have also come from other countries, including Somalia, Ghana, and the former Yugoslavia, and mainly for political reasons. If we include the children of migrants who were born in the Netherlands, $18.7 \%$ of the population in 2003 had a non-Dutch background, 8.8\% had a Western background, and $9.9 \%$ was of non-Western origin (CBS, 2003). Large scale research has established that minority students are, on starting and concluding primary education, two years behind their native Dutch counterparts in language skills and half a year behind in maths skills in terms of national test scores (Tesser et al., 2001). It is generally assumed that cultural differences as well as the nature of the integration process are responsible for these differences, although it is acknowledged that we lack knowledge of the exact nature of the origin of these differences (Jungbluth, 1999).

\subsection{The research project and its methods}

The observations presented here form part of a larger project whose main objective is to understand collaborative learning practices among students in multi-ethnic classrooms both in the context of classroom activities and in out-of-school contexts (Elbers and de Haan, 2004, 2005; de Haan and Elbers, 2004). We are particularly interested in the kind of activities students develop in order to facilitate the joint construction of knowledge in these contexts, i.e., the role divisions they set up, the norms for the joint construction of knowledge, etc. and how these processes are related to (ethnic) diversity. We use a dataset that was collected in the seventh grade of a multiethnic primary school in a large city in the Netherlands (children aged between 10 and 12). The class has 22 students: 5 native Dutch students, and 17 from other backgrounds (12 Dutch-Moroccan, 3 Dutch-Turkish, 1 Dutch-former Yugoslavian and 1 Dutch-Ghanaian). The children are second generation migrants.

For this analysis we selected 4 maths lessons in which students worked together in 5 different groups. The lessons were videotaped to give an overall idea of the classroom activity and audio recorders were placed on each of the tables. Our analysis is based on $20 \mathrm{~h}$ of transcribed material. Two groups consisted of only minority students and 3 groups were 'mixed'. The groups remained the same throughout the observed period: they had been arranged earlier by the teacher, bearing in mind issues of discipline and control as well as heterogeneity (gender and ethnicity).

The school has a philosophy which fosters collaborative learning and actively encourages students to help other students with their work. According to the team of teachers, this is a good way to build a school community, despite students' differences in cultural background (de Haan and Elbers, 2003). The team has been trained 
in collaborative learning skills and has since adopted collaboration between students as a regular strategy. Taking responsibility for one's own learning as a student and that of one's peers and showing respect for each other are central guidelines. According to the school principal, the school fosters a view in which students should ideally learn to guide other students by adopting the role of a tutor ('What do you think the next step would be?'), rather than by adopting a more demonstrative and directive way of working ('just telling them how to do it'). However, it must be added that the school does allow a variety of strategies to develop. The school's maths curriculum supports this vision: students should construct their own mathematical knowledge on the basis of dialogues with their peers. The curriculum is called 'realistic'. Ninety percent of the maths curriculum in the Netherlands is influenced by Hans Freudenthal's (1991) theory on maths teaching, with its key concept of 'realistic contexts' of learning.

In the classroom we observed, all the students are aware that they are expected to arrive at some form of collaboration and that individual work during these group sessions is not valued positively by the teacher. Collaboration in this school is a normative institutional practice. The school therefore inculcates attitudes and competencies in the children which reflect these normative demands. Students have practised and exercised collaboration since grade one.

We analysed the data both qualitatively and quantitatively. Initial qualitative descriptions of the discussions in each group during each lesson focused on how students organized their knowledge-sharing activities, as well as the kind of social context that was created as a result, i.e., the norms and patterns of collaboration and participation that were evident. Subsequently, a quantitative scoring system was designed to process the differences between Dutch students and minority students that had been observed in the qualitative descriptions. Going through the whole database, we selected episodes in which some form of explanatory work took place. We referred to these episodes as Collaborative Learning Episodes or CLEs: episodes in which one student intended to or was asked by another student to share his or her knowledge about the task at hand.

We then characterized these episodes according to the type of activity that was constructed by the students as well as the division of roles that followed from it, making a distinction between two different modes of explanation. The two modes implied a different orientation to how knowledge should be shared. We referred to them as: (a) 'peer-tutoring mode' (based on asymmetric relationships), and (b) 'peer-collaboration mode' (based on symmetric relationships; Foot et al., 1990). The peer-tutoring mode was characterized by the fact that one student took on a teacher role and would structure the activity for the other student, ask questions, evaluate answers, take responsibility for the learning of the other student, be careful not to give the solution right away, and refrain from answering questions or doing tasks while he or she was involved in explanatory work. This mode is similar to what has been called the Child As Performer (CAP) principle. According to the CAP principle, the teacher structures the activity so that the student is able to perform and the teacher refrains from performing (e.g., by asking questions such as 'What do you think you should do next?'; Nilholm and Säljö, 1996). In the peer-tutoring mode, 
students reproduce the CAP principle in the ways they collaborate. In contrast, what typifies the peer-collaboration mode is that the student who is doing the explaining does so while he or she is actually doing the task, accepting contributions from fellow-students as solutions to the problem at hand. This way of working is more similar to 'work' than to 'learning' (Wertsch et al., 1984). Here the solutions from all participants are of the same nature: questions posed are not known-answer questions but simply serve as a means to get information. ${ }^{1}$

\subsection{Different interpretations of collaboration: learning or work?}

Let us start by giving one example each of the two modes, then present quantitative information on the occurrence of the modes, and, finally, discuss in detail the circumstances under which these modes are applied by the students.

\subsubsection{The two modes: examples}

In the peer tutoring episode presented in excerpt 1 below, the students are working on a task about a store where candy can be bought either in small, regular packets or in a large family-size pack. The assignment requires them to calculate how many small boxes can be put into a larger box. Excerpt 1 comes at the beginning of the interaction in group 3, immediately after the teacher introduced the task and told the children to start working together. The group consists of Goran, a Dutch-Yugoslavian boy, Maktoub, a Dutch-Moroccan boy, Annelies, a Dutch girl and Berend, a Dutch boy. In this example Annelies takes the initiative to explain to the others.

Excerpt 1 (Group 3, 5-6-00)

\begin{tabular}{ll}
\hline (1) Annelies: & OK. Problem 4. How many times does a standard \\
& packet fit into the family pack? Now, $\uparrow$ work it out. \\
(2) Maktoub: & One, two three \\
(3) Annelies: & What \\
(4) Maktoub: & Three times \\
(5) Annelies: & No:. Think lo...:.gically. \\
(6) Goran: & ((reads)) How many times does $=$ \\
(7) Annelies: & =Look. \\
(8) Goran: & How many times? \\
(9) Annelies: & $(.)>$. Yes<. Look. Standard packet, three times like this... \\
(10) Maktoub: & and three [times... \\
(11) Annelies: & You should take that three times, because the \\
& three here is also here. \\
(12) Maktoub: & Yes.
\end{tabular}

\footnotetext{
${ }^{1}$ The scoring for the two modes proved reliable (Cohen's $\left.\kappa=.84\right)$. Furthermore, while focussing on what happened within the CLEs, we noted who was doing the explaining and to whom it was addressed.
} 
(13) Annelies:

(14) Goran:

(15) Annelies:
And three goes three times into nine, so you should take it three times. Three times nine is twenty-seven. Say it again.

Do you understand?

This episode shows how Annelies takes on a tutor role and assumes responsibility for Maktoub's and Goran's learning - she gives them instructions, provides feedback, and checks if they understand. She does not work on the problem with Goran and Maktoub on an equal basis but takes responsibility for their learning as she asks them to start working on the problem (turn 1), encourages them to think harder (turn 5), corrects their answers (turn 5), confirms their correct answers (turn 9), and checks that they understand (turn 15). She makes sure that she is not the one who does this assignment but allocates this role to Maktoub or Goran in line with the CAP principle.

In the second pattern of knowledge sharing, the peer-collaboration mode, we found a different division of roles and way of organizing the activity. Below is an episode which illustrates this mode. It is taken from Group 1, which has only minority children (Feliz, a Dutch-Turkish girl, Samira, a Dutch-Moroccan girl, Assad, a Dutch-Moroccan boy, and Hassan, a Dutch-Moroccan boy). There is a clear contrast with the excerpt from the mixed group presented above. The task is the same as in excerpt 1, but Hassan, although he is clearly explaining things, does not adopt a tutor position.

Excerpt 2 (Group 1, 5-6-00)

(1) Hassan: One, two, three

(2) Assad: Three times three, is what?

(3) Samira: I am here

(4) Assad: One, two, three, four, five, six, seven, eight, nine.

(...)

(5) Assad: ((counts up to twenty-seven))

(6) Hassan: For, here, this is (.) twelve centimetres, and here it fits three times, so three boxes fit here like this, and $=$

(7) Samira: =Three boxes fit=

(8) Hassan: =And (.) going up three boxes also fit, isn't that right?=

(9) Samira: =Yes, because three times three is [nine, four times three is twelve.

(10) Hassan:

[Here three, here three, and here three, and here

(11) Samira: How do you do that?

(12) Hassan: Just like that.

(...)

((Hassan sits opposite Samira. He now walks to

Samira's side of the table.)) 
(13) Hassan: Look here, twelve centimetres. ( ) Three times, so, three, (.) three boxes like this $>$ and then we look at the height $<$. Here it also fits three times, so three boxes up, three boxes like this, and here also three times, so three boxes up, here three.

What we see is that Hassan clearly adopts a leading role in the interaction by sharing his solutions with the group both on his own initiative and on the initiative of the others. He is acknowledged as a good maths performer in this group and his enthusiasm is clear from his eagerness to explain repeatedly to the others. However, his role is still not like the role of a tutor as he does not take responsibility for the learning of the others, he simply makes it clear to the others how he is working, doing the job himself (instead of asking the other students to do it). Pointing to the picture in the maths book, he demonstrates the respective steps he is taking (e.g., in turns 6, 10 and 13) on an egalitarian basis. The role of the expert in this group is, in principle, interchangeable. This is clear, for instance, from turns 7 and 9 where Samira contributes to the knowledge building while confirming the solution (in turn 7) and arguing why (in turn 9) Hassan's solution is the right one. However, immediately after that she takes on a more dependent role in turn 11 when she invites Hassan to explain. Typically, the questions posed here are not known-answer questions but questions that make use of the other student's expertise, as in turn 2 when Assad poses a multiplication question. What is typical of this pattern is that all the participants in the group can take the initiative, adopt leading roles, and are consulted for the specific skills they have.

\subsubsection{The two modes: quantitative analysis}

Table 1 shows the distribution of CLEs over the modes and groups. Although the peer-collaboration mode was the mode that was most frequently adopted in all groups, the peer-tutor mode occurred relatively more frequently in the groups where minority and Dutch students worked together. Within the CLEs we also counted who it was that did the explanatory work and to whom it was addressed. Almost $72 \%$ of all explaining actions was done by Dutch students and addressed to minority students. In only $6 \%$ of the cases minority students offered explanations to Dutch students, and this only occurred in the peer-collaboration mode. We checked the effects of proficiency in maths on explanatory behaviour by dividing up the students into high performers and low performers. These two groups did not differ in their

Table 1

CLEs per mode in mixed and minority-only groups

\begin{tabular}{lll}
\hline & Peer-tutor mode & Peer-collaboration mode \\
\hline Minority groups & $8(6.2 \%)$ & $122(93.8 \%)$ \\
Mixed groups & $35(25.4 \%)$ & $103(74.6 \%)$ \\
Total & $43(16.0 \%)$ & $225(84.0 \%)$ \\
\hline
\end{tabular}

$N=268$ CLE, $\chi^{2}=18.34, d f=1, p<.00$. 
explanatory behaviour. Within the group of minority students, no differences between high and low maths performers were found related to explanatory behaviour. We could not make a similar analysis for the Dutch group as this group was small and the students were all high maths performers.

\subsubsection{The two modes: contexts and negotiations}

Let us now examine in detail the context of the CLEs. In what circumstances do students use the peer-tutoring mode rather than the peer-collaboration mode and vice versa? To answer this question, we have singled out episodes in which the collaboration and the mode of collaboration were being discussed or questioned. Such self-reflexive episodes are particularly useful for understanding students' motives for applying one or other of the modes. There is a lot of negotiation going on during the process. This negotiation is mostly directed to norms of participation (who is entitled to participate and how) and conditions for adopting certain roles, in particular the tutor role. It is precisely this kind of negotiation that shows that these modes are local student productions under given institutional and cultural conditions.

The first example is taken from a discussion in group 1 with only minority students. This group has developed a strong preference for the peer-collaboration mode. The exchange of expertise on an equal basis is an important norm in this mode. We present an episode at the end of a lesson. One of the students, Feliz, seems at this stage to be one step behind the others in the group. The episode shows how the other students react to this.

\section{Excerpt 3 (Group 1, 5-6-00)}

\begin{tabular}{ll}
\hline (1) Samira: & So the first is two thousand, two hü::ndred, two thousand \\
(2) Feliz: & Is the first two thousand? \\
(3) Hassan: & ((irritated)) Hey man. \\
(4) Samira: & >You only want to copy it<, come on \\
(5) Feliz & ((irritated) $>$ I don't under $\uparrow$ stand, you understand<-. \\
(6) Samira: & Yes, you don't work with us. \\
(7) Hassan: & Two thousand \\
(8) Feliz & I do. But you don't tell me anything. \\
(9) Hassan: & We say nothing. You do nothing. \\
(10) Samira: & Because you don't work with us. \\
(11) Hassan: & (...) \\
(12) Feliz: & Do you know why we say nothing, because you should \\
(13) Assad: & have your own ( ).
\end{tabular}

In this episode, Feliz (turn 2) asks the others to tell her about the solution to the problem they have been working on for a while. Obviously, the others do not see her as being part of this collective process as they accuse her of copying (turns 3 4). Feliz's defence that she does not understand is not acknowledged by the group. 
Acting as tutee, i.e., someone who does not know and needs to have things explained to him/her, invites criticism, as is clear from the rest of the episode in which the others stress active membership of the group is stressed as a condition for sharing solutions; see, for instance, turn 6 in which Samira states that Feliz should work with them. Also in turn 9 Hassan makes the connection between being part of the process (doing) and being part of the solution (saying). Assad confirms this in turn 13 where he explicitly does not acknowledge 'the need to explain' and puts forward 'working with the group' as an imperative. This episode shows that the student's collaboration implies certain norms of participation and knowledge sharing and also that these norms are consistent with the peer-collaboration mode and contrast with the peertutor mode. These norms are made explicit in situations where someone does not play the game according to the rules, as in Feliz's case.

The second situation is taken from a conversation in a mixed group, in which the Dutch student Lonneke is criticized for not being a good enough tutor. The group consists of Lonneke, a Dutch girl, Ikram, a Dutch-Moroccan girl, Françoise, a Dutch-Ghanaian girl, Abdel, a Dutch-Moroccan boy, and Fahd, a Dutch-Turkish boy.

Excerpt 4 (Group 4, 26-5-00)

(1) Lonneke: Look, here, hundred and seventy, uh.. hundred??

(2) Ikram: Yes it is.

(3) Ll?: $\quad$ Four.

(4) Fahd: $\quad$ She just does not know how. She is just doing something (...)

(5) (): $1,2,3,4,5,6,7$.

(6) Abdel:

They are so stupid.

(7) Lonneke: $\quad$ You are stupid.

(8) Fahd: Yeah.

(9) Abdel: $\quad$ Yeah, and she ((meaning Lonneke)) gives you all the answers.

(10) Fahd:

Ye:::s. But after that she acts stu:pid.

(11) Ikram:

Hello:: But you don't have to give all the answers.

(12) Françoise: $\quad$ Yes and you (...) You don't have to give all the answers.

Yesterday you wrote down all the answers she

((Lonneke)) gave you.

(13) Ikram: You could also (...) ehh (..) it's better to explain.

(14) Lonneke: Yes.

After Lonneke's attempts to show something to Ikram (turn 1), Fahd states that Lonneke does not know how to explain (turn 4), that she is being stupid (turn 10), which picks up on a generalisation that 'they are so stupid' in turn 6 (this turn probably refers to the Dutch students in general). The group further discuss 'explaining' in turns 9 to 13 contrasting it to 'giving away the answers' and expressing a (principled) preference for explaining. Françoise accuses Lonneke of giving away answers, and she includes Ikram in her accusation since she is the one who copied Lonneke's answers. In this way, criticizing Lonneke turns into a more general reflec- 
tion of the group's way of working and leads to an explicit statement about the advantages of explaining (in turn 13).

Our next example is particularly revealing because it shows how students in a minority-only group evaluate the peer-tutor mode. This excerpt is one of the few cases where this mode is used by minority-only groups. The excerpt presented below is taken from a group of 4 Dutch Moroccan students, two girls, Fouzia and Ilham, and two boys, Ferit and Zakaria. The episode comes after 15 min of group work and is a reaction to an intervention by the teacher who provides feedback to the group. In this intervention, Fouzia is the most active student. She answers most of the teacher's questions. The teacher concludes that Fouzia has understood the problem that they are working on, viz. how many small boxes can be put into a larger box, taking into account their volume. The teacher then instructs Fouzia to explain her solution to the others.

Excerpt 5 (Group 2, 5-6-00)

(1) Teacher: ((addressing Fouzia)) Explain it to your group, so that they understand ((she leaves))

$(\ldots)$

(2) Fouzia: Look, you do the length. O.k., first we calculate the length.

(3) ((Other students laugh))

(4) Fouzia: O.k., now the length, what is the length?

(5) ( ): Three centimetres

$(\ldots)$

(6) Fouzia: How much is it upwards? ((laughs))

(7) Zakaria: Four centimetres.

(8) Fouzia: ((laughing)) How long is it?

(9) Ilham: Three centimetres.

(10) Ferit: Three centimetres.

(11) Ilham: You should take this one.

(12) Student: O.k., here three centimetres.

(13) Ilham: Three

(14) Fouzia: Well done, and what about the width?

(15) Ilham: Fifteen.

(16) Fouzia: Yes, how do you know?

(17) Student: ( ) fifteen centimetres.

(18) Fouzia: ((laughs)) That is the solution.

The fragments in excerpt 5 show that Fouzia is taking on a tutor's role. Although she does perform the role with certain fluency, she treats it as a temporary role in a way which resembles play or parody (rather than displaying a regular aspect of her behaviour). The laughter on the part of both Fouzia and the others is significant in this respect and shows a certain amount of embarrassment. Our interpretation here is affirmed by a number of observations: Fouzia performs this role 'on 
command' (turn 1); in the lessons we observed she only did this during one lesson; and she is criticized by the others after a while, who tell her: "Don't talk like this".

\section{Across contexts: tutoring as a local reworking of "off-site" repertoires and relationships}

How do we interpret these data in the light of a cross-contextual perspective? Our first point is that our results show that the patterns we have detected are local productions, i.e., specific responses to a particular institutional environment. Next, we wish to stress the ways in which 'culturalist' and 'structuralist' perspectives add to our analysis and how, when interwoven with a local production perspective, they prove to be fruitful as part of a cross-contextual explanation. Finally, we consider how these kinds of explanations can contribute to reflections on cultural translation and change.

\subsection{Tutoring and collaboration as student work: local productions}

Our analysis has shown that the students in this classroom do not just take on or invent the two different modes of collaboration described above as if they were ready to pick them up, only for them to apply. The peer-tutor mode is, like the peercollaboration mode, not a self-evident practice, which students reproduce automatically in response to institutional norms. Instead it is an active, collective production of students. It is a creative response to the institutional demands to work together collaboratively and 'explain' things to each other. In particular the struggle with group norms on participation and the conditions under which a student can take on a tutor role prove that these are dynamic practices in which normative roles are tested and appropriated in particular ways. The Fouzia example (excerpt 5) and the Lonneke examples (excerpt 4) show that, although peer tutoring is, in this classroom, related to Dutch-minority relationships, local conditions may change or challenge such a pattern. ${ }^{2}$

With respect to how these two patterns are linked with ethnic divisions in this class, we can say that, although peer tutoring seem to be strongly linked to Dutch Native students (as they are the ones who apply the mode most frequently), the data also show that they do so when involved in a particular ethnic relationship, that is, when they explain things to minority students. We have also seen that minority students are able to act out this tutor role, playfully in particular circumstances (see especially excerpt 5).

All in all, we can say that the observed patterns must be seen both as responses to a particular local setting and as active re-workings of the conditions of this setting

\footnotetext{
${ }^{2}$ The discussion of the conditions under which students are entitled to participate in the peercollaboration mode, in which the norms of 'actively working together' and 'equal participation' are discussed, shows that this is an active student construction, even more so, as this is a pattern which is in a certain sense opposite to the tutor model which the school promotes (see above).
} 
and that, in addition to having a certain robustness about them in the sense that they repeatedly turn up in the same form, they are also clearly situated and flexible.

\subsection{Cultural and structural 'givens'?}

Let us now turn to a 'culturalist' perspective. On the basis of a review of the literature on Moroccan socialisation (Pels and de Haan, 2003), it can be argued that 'tutoring' in the sense of adults consciously intervening in the child's learning, structuring their learning experience (or 'direct instruction') is not a common practice in Moroccan socialization. Such tutoring does occur commonly in Dutch middle class families. Children in Moroccan families learn through modelling and observation of adults and participate in relatively 'free' and open peer spaces where symmetric forms of participation are dominant. Although we concentrate here on (traditional) Moroccan versus Dutch middle class, the same contrast is found between other white middle class cultures and non-western cultures (Rogoff, 2003; Paradise, 1994; de Haan, 1999). The literature on Moroccan migrants in the Netherlands shows that peer socialization is relatively more influential for Moroccan children than for Dutch children, for instance, with respect to the support which peers and siblings offer one another in school work. So, if we speak from the point of view of what is known about the students' home socialization, we could say that Moroccan students are less familiar with a socialization mode in which adult intervention and 'direct instruction' is common and that this helps explain why, unlike the Dutch students, they do not readily pick up a role pattern that is based on an asymmetric, one-to-one adult-child relationship. In contrast, from what we know of their home socialization, we can expect them to pick up more symmetric modes of interaction that are based on the equal participation and status norms which characterize the peer socialization they are familiar with. The Dutch students, being more familiar with one-to-one asymmetric 'direct instruction', are more likely to borrow from this model, especially perhaps in circumstances which encourage such an asymmetry.

Alternatively, if we think in more 'structuralist' terms, then the different engagements in modes of collaboration can be explained by referring to a different academic engagement of migrant students which is based on more structural inequalities between Dutch and migrant groups outside this classroom. If we combine notions of resistance theory (Giroux, 1983) and minority status theory (Ogbu, 1991), we can see minority students' reluctance to adopt a tutor position as an expression of the distance these students experience with the institution of schooling. This is mediated by a sense that the institution is not working for them in the same way as it does for native Dutch students and such a perception is based on more structural power inequalities that exist between them elsewhere in society. In the general literature on minority and schooling, disengagement and the adoption of a distant attitude as a consequence of how students think the institution works for them is amply documented. The Dutch literature on minority parents' attitude (Pels, 1998) as well as on minority students' attitude (Andriessen and Phalet, 2002) on schooling in the Netherlands provide proof of a certain distance towards 
schooling that is related to skepticism that the institution will mediate their (children's) school careers in fair ways. In the light of these studies, the reluctance to use the peer-tutor mode can be seen as a way of establishing a distance with the school standards and the school models of learning and teaching, so as to create alternative spaces and work forms. Moreover, the fact that the tutor-tutee relationship is expressed in Dutch-minority relationships and that the minority students come to take on the more dependent positions means that this is not just a response of minority students to schooling but an interactive pattern which provides or is appropriated as an opportunity to express and confirm power inequalities that exist elsewhere.

\subsection{Cross-contextual explanations and cultural translation}

As argued in the introduction, we see the collaboration patterns that have evolved in this multi-ethnic classroom both as particular, situated, productions of this setting and as a translation of processes and patterns that are more enduring and robust. We see the classroom as a space in which the cultural patterns and power relationships that students bring along are reshaped, resisted and developed further. The situated, local side of this phenomenon becomes clear when we consider the creative efforts which students make to adopt the institutionally given norms on collaboration and the particular forms through which such adoptions are negotiated. It is clear that these forms are the student's own versions of what the institution demands from them. At the same time, the particular forms that are being developed 'match' cultural patterns and social relationships and attitudes which exist outside this class (the culturalist and structuralist explanations). We believe that this 'matching' is a process of creative translation between contexts where 'old' forms are reproduced in 'new' ways. That is, from the differences in socialization experiences we were not able to predict how the variety in collaboration patterns in peer groups in a school context would emerge. These were the specific local circumstances that shaped the socialization patterns and ethnically informed power relations specific to the institution, providing them with their current form.

In our view, structural and cultural aspects can be mutually formative. The difference in domestic experience with adult-led direct instruction between the Dutch and minority students has induced a pattern in which tutor roles were mostly taken up and given to the Dutch students. But at the same time, the particular power relationships between migrant students and Dutch students structured the possible field of action in which such a division of roles became possible. The unequal power relationships between minority students and Dutch students found a cultural expression in the development of a tutor-tutee relationship in an academic setting. The 'original' cultural patterns, i.e., those that exist 'elsewhere', were re-interpreted in interaction with the social positions and relationships that were constructed as a result of a shared history in this particular class. Similarly, the power relationships in Dutch society and how they shape the students' identification with school can be seen as a condition for the development of a more dependent position of minority students 
in the tutor-tutee relationship. It is in this process of re-interpretation and adjustment that new cultural forms and social positions are being created. The status relationships between Moroccan and Dutch students are reworked as they get a particular form in tutor-tutee relationships and these status relationships may evolve in different ways from how they exist outside the classroom. Likewise, the culturally informed experiences of collaboration and tutoring which students bring into the classroom evolve in new ways due to the social and cultural dynamics of this classroom. It is here that the idea of 'art of the present' becomes relevant, as it is in these particular local settings that cultural patterns and social relationships are articulated and pushed into new directions due to the contradictions and confrontations of that situation.

In this particular setting, migrant students and Dutch students are confronted with specific institutional demands as well as a diversity of experiences and positions which is brought along. Students are forced to develop a liveable and workable form which mediates between, on the one hand, what they know and are experienced in and, on the other hand, what matches the dynamics of this academic setting. The perspective taken in this paper invites attention to several historical durées (including how they are articulated in the here and now); it includes different social levels or scales of analysis and considers in detail how these are locally expressed by making the processes of translation visible. For instance, this study shows that migrant students develop a particular form of peer collaboration that can be traced back to traditional Moroccan patterns of peer socialization. It also shows how this is made to function in an academic environment in line with a 'modern' pedagogy of collaborative learning as advocated by the institution.

Allow us to conclude by stressing how an understanding of diversity involves both an eye for the specifics and dynamics of local productions and the non-local structures and cultural patterns that are brought to bear on these productions. The challenge is to move the analytic eye in multiple directions and trace cultural patterns and power relations 'back and forth' to other settings and time scales. It is only in such a perspective that both the dynamic and the resistant nature of diversity can be framed adequately.

\section{References}

Andriessen, I., Phalet, K., 2002. Acculturation and school success. Intercultural Education 13, 1-36. Bhabha, H.K., 1994. The Location of Culture. Routledge, London.

Bourdieu, P., Passeron, J., 1977. Reproduction in Education, Society, and Culture. Sage, London. Centraal Bureau voor de Statistiek (CBS), 2003. Kerncijfers van de allochtonenprognose 2000-2050. CBS, Heerlen.

Cazden, C.B., 1986. Classroom discourse. In: Wittrock, M.C. (Ed.), Handbook of Research on Teaching. MacMillan, New York, London, pp. 432-463.

Eisenhart, M., 2002. Changing conceptions of culture and ethnographic methodology: Recent thematic shifts and their implications for research on teaching. In: Richardson, V. (Ed.), The Handbook of Research on Teaching, fourth ed. Macmillan, New York, pp. 209-225. 
Elbers, E., de Haan, M., 2005. The construction of word meaning in a multicultural classroom mediational tools in peer collaboration during mathematics lessons. European Journal of the Psychology of Education 20 (1), 45-59.

Elbers, E., de Haan, M., 2004. Dialogic learning in the multi-ethnic classroom. Cultural resources and modes of collaboration. In: Van der Linden, J., Renshaw, P. (Eds.), Dialogical Perspectives on Learning, Teaching and Instruction. Kluwer Academic Publishers, Dordrecht, pp. 17-43.

Foot, H.C., Morgan, M.J., Shute, R.H., 1990. Children's helping relationships: an overview. In: Foot, H.C., Morgan, M.J., Shute, R.H. (Eds.), Children Helping Children. Wiley, Chichester, pp. 3-17.

Freudenthal, H., 1991. Revisiting Mathematics Education. Kluwer, Dordrecht.

Gallego, M., Cole, M., 2002. Classroom cultures and cultures in the classroom. In: Richardson, V. (Ed.), The Handbook of Research on Teaching, fourth ed. American Educational Research Association, Washington, DC, pp. 951-997.

Giroux, H.A., 1983. Theories of reproduction and resistance in the new sociology of education: a critical analysis. Harvard Educational Review 53 (3), 257-293.

de Haan, M., 1999. Learning as cultural practice. How children learn in a Mexican Mazahua Community. A study on culture and learning. Thela Thesis, Amsterdam.

de Haan, M., Elbers, E., 2003. Samenwerkend leren. Zone. Tijdschrift voor ontwikkelingsgericht onderzoek 2 (2), 4-6.

de Haan, M., Elbers, E., 2004. Minority status and culture: local constructions of diversity in a classroom in the Netherlands. Intercultural Education 15 (4), 441-453.

Holland, D., Skinner, D., Lachiotte Jr, W., Cain, C., 1998. Identity and Agency in Cultural Worlds. Harvard University Press, Cambridge, MA.

Heath, S.B., 1983. Ways with Words. Language, Life, and Work in Communities and Classrooms. Cambridge University Press, Cambridge.

Jungbluth, P., 1999. School careers, social class and ethnicity. Nederlands Tijdschrift voor Opvoeding, vorming en onderwijs 15 (3), 182-196.

Levinson, B.A., Holland, D., 1996. The cultural production of the educated person: an introduction. In: Levinson, B.A., Foley, D.E., Holland, D. (Eds.), The Cultural Production of the Educated Person. Critical Ethnographies of Schooling and Local Practice. State University of New York, Albany, pp. 155.

Lock Davidson, A., 1996. Making and Molding Identity in Schools. Student Narratives on Race, Gender, and Academic Engagement. State University of New York Press, Albany.

Mehan, H., 1998. The study of social interaction in educational settings: Accomplishments and unresolved issues. Human Development 41, 245-269.

Nilholm, C., Säljö, R., 1996. Co-actions, situation definitions and sociocultural experience. Learning and Instruction 6 (4), 325-344.

Ogbu, J., 1991. Immigrant and involuntary minorities in comparative perspective. In: Gibson, M.A., Ogbu, J. (Eds.), Minority Status and Schooling. A Comparative Study of Immigrant and Involuntary Minorities. Garland Publishing, Inc., New York, pp. 3-33.

Ortner, S.B., 1999. The Fate of Culture. Geertz and beyond. University of California Press, Berkeley.

Papastergiadis, N., 2000. The Turbulence of Migration. Globalization, Deterritorialization and Hybridity. Polity Press, Cambridge.

Paradise, R., 1994. Interactional style and nonverbal meaning: Mazahua children learning how to be separate-but-together. Anthropology \& Education Quarterly 25, 156-172.

Pels, T., 1998. Opvoeding in Marokkaanse Gezinnen in Nederland. De Creatie Van Een Nieuw Bestaan. Van Gorcum, Assen.

Pels, T., de Haan, M., 2003. Continuity and Change in Moroccan Socialization. A Review of the Literature on Socialization in Morocco and among Moroccan Families in the Netherlands. Verwey Jonker Institute \& Utrecht University, Utrecht.

Rogoff, B., 2003. The Cultural Nature of Human Development. Oxford University Press, Oxford.

Tesser, P.T.M., Dagevos, J.M., Iedema, J., 2001. Rapportage Minderheden 2001: Samenvatting Vorderingen Op School En Meer Werk. SCP, Den Haag. 
Wertsch, J.V., Minick, N., Arns, F.J., 1984. The creation of context in problem solving. In: Rogoff, B., Lave, J. (Eds.), Everyday Cognition: Its Development in Social Contexts. Cambridge University Press, Cambridge, pp. 151-171.

Mariëtte de Haan works at Utrecht University, the Netherlands as a researcher and teacher. Her research focuses on Native American learning, collaboration processes in multi-ethnic classrooms in the Netherlands and strategies of migrant families to deal with formal schooling in the Netherlands.

Ed Elbers is Professor of Communication, Cognition and Culture at Utrecht University, the Netherlands. His main research theme is interaction and communication in learning and instruction. His recent work focuses on collaboration and learning in multi-ethnic classrooms. 